\title{
PUERTO RICO Y ESPAÑA: SIGLOS DE UNIÓN
}

\author{
Olga A. Figueroa Miranda \\ Observatorio de Arecibo. Universidad Central de Florida (Puerto Rico)
}

$\mathrm{F}$ ste monográfico nos adentra en la unión transatlántica entre la isla del Caribe, Puerto Rico, y España. A tres mil kilómetros de distancia y a siglos de dejar de ser territorio español, Puerto Rico se mantiene con profundos lazos con la «madre patria», como muy cariñosamente le llaman los puertorriqueños a España. Puerto Rico durante cuatro siglos perteneció a la corona española, desde su descubrimiento por parte de Cristóbal Colón en 1493 hasta 1898. A pesar del pasar del tiempo, vemos cómo mantiene viva su conexión con España en gran diversidad de aspectos, no tan solo por el idioma, sino también en ámbitos religiosos, políticos, sociales, culturales y gastronómicos. A través de las lecturas, veremos plasmada la diversidad de estas magníficas conexiones.

En las aportaciones de estos autores, a pesar de presentar temas tan variados, podemos apreciar los lazos estrechos que aún existen entre Puerto Rico y España. El autor Pérez Colón explica en su escrito cómo la relación entre Puerto Rico y España entra en un período de transición debido a las situaciones políticas de ambos países, pero cómo a su vez los vínculos de cuatrocientos años de historia mantienen viva la conexión entre ambos países. Por otro lado, la autora Álvarez Curbelo presenta la popularidad de estilos arquitectónicos españo- les en edificios públicos y privados de Puerto Rico. Muestra así que, a pesar de los cambios culturales experimentados en la isla tras convertirse en colonia de Estados Unidos, las ataduras simbólicas con España permanecen vivas. Por su parte, el presidente de Iniciativa Puerto Rico-España, Ignacio Salinas, comparte la rica historia, los lazos culturales, el idioma y la forma similar de entender y disfrutar la vida en estos países ricos en cultura e historia. Además, explica cómo la Iniciativa Puerto Rico España trabaja para que Puerto Rico sea conocido en España y cómo desde España desarrollan iniciativas para ayudar a la isla. Los autores Paradinas Zorrilla, Monsalve Gil-Fournier y Gracia de Torres dan a conocer varios datos de la isla acerca de los aspectos económicos y las relaciones bilaterales con España. También muestran las oportunidades que ofrece la isla en turismo e infraestructuras, entre otros sectores.

Una vez más vemos la importancia y el sentido del Atlántico que nos une. Lecturas como estas nos llevan a pensar sobre este fenómeno transversal entre ambas orillas. En lo conocido y desconocido que este océano continúa relacionando. Nos mantendremos reflexionando entre el Nuevo y el Viejo Mundo. 